\title{
Evaluation of the health behaviors of women in multiple pregnancies - a preliminary study
}

\author{
Anna B. Pilewska-Kozak' ${ }^{1}$, Beata B. Dobrowolska ${ }^{2}$, Joanna Tkaczuk-Włach ${ }^{1}$, \\ Grażyna Stadnicka ${ }^{3}$, Celina Łepecka-Klusek ${ }^{1}$, Klaudia Pałucka ${ }^{4}$, Magdalena Ziółkowska ${ }^{4}$ \\ ${ }^{1}$ Chair and Department of Gynecology and Gynecological Endocrinology, \\ Faculty of Health Sciences Medical University, Lublin, Poland \\ ${ }^{2}$ Chair of Development in Nursing, Faculty of Health Sciences, Medical University of Lublin, Poland \\ ${ }^{3}$ Department of the Basics of Midwifery, Faculty of Health Sciences, Medical University of Lublin, Poland \\ ${ }^{4}$ Graduate of the Faculty of Health Sciences, Medical University of Lublin, Poland
}

\begin{abstract}
Objectives: The aim of the paper was to assess which health behavior indicators were characteristic for women with a multiple pregnancy.

Material and method: The study involved 35 women in multiple pregnancies. The inclusion criteria were: the completion of the $22^{\text {nd }}$ week of pregnancy ( $22 \mathrm{Hbd}$, i.e., 22 weeks and $1 / 7$ ) and the consent of the women to participate in the study. We used an original questionnaire devised by us specifically for our study, as well as a standardized research tool, Juczyński's Health Behavior Inventory questionnaire, for the assessment of the pregnant women's health behaviors.

Results: The overall rate of health behaviors was high and was on average $93.9 \pm 10.8$ points (7 sten scores). Indicators of the health behaviors of women in multiple pregnancies were high across all categories. However, the highest rate was observed in preventive behaviors.

Conclusions: The overall rate of health behaviors of women with a multiple pregnancy and all the individual behavior category indicators were high. However, the highest rate was for preventive behaviors. The indicator values of the health behaviors of the pregnant women in the study were not dependent on the variables adopted in this paper.
\end{abstract}

Key words: health behavior, multiple pregnancies

Ginekologia Polska 2018; 89, 6: 289-294

\section{INTRODUCTION}

Bearing in mind the Lalonde concept, some authors reports that human health in all its dimensions depends on many factors and that is proportionally determined by lifestyle $(50 \%)$, social environment $(25 \%)$, remedial medicine (10-20\%), physical environment (5-10\%), and genetic factors (5-15\%) [1]. The study reports that health behaviors are the most significant factor influencing human lifestyle.

To a large extent, the correct course of pregnancy, the intrauterine development of the child and their further development after labor, depend on the health status of the woman during the preconception and pregnancy periods [2-15]. Physical activity adjusted to the possibilities of the woman's body; optimal nutrition, sleep and leisure; as well as good family relations and access to medical care all have beneficial effects on pregnancy health. On the other hand, negative health behaviors occur in relation to nutrition; a lack of physical activity, sleep and rest time; and the dangerous use of stimulants, such as alcohol, cigarettes or psychoactive substances [16-27].

Pregnancy is a good time for health promotion, aimed at changing previous negative habits. Correct changes to eating habits and lifestyle during pregnancy have a positive effect on the gestational age of the newborn, their birth weight and Apgar score [2-15].

Multiple pregnancies belong to the category of so-called high-risk pregnancies [16-18]. Sometimes a woman requires hospitalization during such a pregnancy. People providing 
preventive care for a woman during multiple pregnancy should pay attention to her health behaviors. In addition, women should avoid some of their previous habits and addictions from the very first weeks of pregnancy.

\section{Objectives}

The aim of the study was to assess which health behavior indicators were characteristic for women in multiple pregnancies.

\section{MATERIAL AND METHODS}

The study involved 35 women who had a multiple pregnancy. It was carried out over a period of 10 months in 2014 and 2015 in three Pregnancy Pathology Departments in Lublin: Independent Public Clinical Hospital No. 1, Independent Public Clinical Hospital No. 4, Stefan Cardinal Wyszynski Regional Specialist Hospital. The criteria for inclusion in the study group were: the completion of the $22^{\text {nd }}$ week of pregnancy ( $22 \mathrm{Hbd}$, i.e., 22 weeks and 1/7) and the written consent of the women to participate in the study.

Our survey method included the use of a questionnaire devised by us specifically for our study, and it covered the study subjects' sociodemographic data and included questions about the women's physical activity before hospitalization, consumption of coffee and alcohol during pregnancy, smoking, and narcotics use. The subject's hospital records were also analyzed to determine their reproductive histories, hospitalizations and the durations of their pregnancies. In addition, - a second, standardized questionnaire, Juczyński's HBI (Health-Related Behavior Inventory) was used to assess indicators of the women's health behaviors [28]. Juczyński's questionnaire includes 24 statements relating to those health behaviors exhibited by study participants in the 12 months prior to data collection and categorized according to four factors: (1) proper nutritional habits (PNH), (2) preventive behaviors [PBs], (3) health practices [HPs], and (4) positive mental attitude [PMA]). In these factors, PNH includes, above all else, the kinds of the food eaten (e.g. whole wheat bread, vegetables and fruit). PB covers whether recommendations are followed or not, and the subject's acquisition of information about health and diseases. HPs include everyday habits related to sleep and recreational or fitness activities. PMA includes the woman's ability to manage strong emotions, stress, tension, or depressing situations. Overall, the idea of $\mathrm{HBI}$ is that it covers three main human behaviors [28]: (1) those that are known to either decrease or increase the risk of disease; (2) those which arise from the person's conviction that they contribute to maintaining good health or to reducing the threat of disease; and (3) those related to obeying medical recommendations. Using the $\mathrm{HBI}$, our study achieved good psychometric properties with both healthy and ill adults
[28]. We asked our study participants to indicate how often they exhibited the health behaviors listed in the questionnaire, using a five-point scale: 1 = almost never; 2 = rarely; 3 = from time to time; $4=$ often; and $5=$ almost always. The values indicated by the respondents were aggregated to obtain the sum of intensification for each health behavior indicator; consequently, scores ranged from 24 to 120 . The higher the scores, the higher the intensification of the HB. The overall $\mathrm{HBI}$ was converted to standardized values: sten scores (from 1-10). The results, calculated for each dimension, ranged from 1-4 sten scores (low HBI), 5-6 sten scores (average $\mathrm{HBI}$ ), and 7-10 sten scores (high $\mathrm{HBI}$ ).

The questionnaires were presented to the eligible participants along with an information sheet describing the study aims and providing an assurance of anonymity. Each participant was given an informed consent declaration to read and sign. The time taken to complete the survey was no more than five minutes.

The Bioethical Commission of the Medical University in Lublin approved the study's research protocol (KE0254/223/2014; 26th June 2014).

\section{Statistical analysis}

The study data was subjected to statistical and descriptive analysis. In the case of variables measured in the nominal and ordinal scale, the frequency and percentage of individual categories were calculated. In the analysis of quantitative variables, measures of descriptive statistics were used: arithmetic mean, standard deviation, median, minimum, and maximum value.

Due to parametric test assumptions not being fulfilled, the Mann-Whitney $U$ test was used. The significance level $p<0.05$ was assumed, to indicate the existence of statistical differences. Database and statistical analyses were carried out using IBM SPSS Statistics computer software (version 21).

\section{RESULTS}

The ages of the examined women ranged from 23 to 45 years (the average age was $30.1 \pm 4.3$ ). At the time of the study, women were on average at $30.7 \pm 4.7$ weeks of pregnancy. More than half of surveyed women $(21 ; 60.0 \%)$ were urban dwellers, and the remaining 14 (40.0\%) lived in rural areas. The majority $(30,85.7 \%)$ of them were married and $5(14.3 \%)$ were in civil partnerships. 25 (71.4\%) of the respondents had higher education, and $10(28.6 \%)$ only secondary education. One in three $(10,28.6 \%)$ respondents were in their second pregnancy, one in four $(9,25.7 \%)$ in their third pregnancy and $16(45.7 \%)$ in their first pregnancy. The majority of women $(32,91.4 \%)$ replied that conception occurred naturally, and 3 (8.6\%) women said their pregnancies resulted from in vitro fertilization. More than half of the women $(22 ; 62.9 \%)$ claimed that during their current pregnancy 
(before hospitalization) they were not physically active, and $13(37.1 \%)$ reported having an active lifestyle. More than half of the pregnant women $(20 ; 57.1 \%)$ reported that they had never smoked and did not smoke during the survey, and $6(17.1 \%)$ reported that they had stopped smoking after their pregnancy was diagnosed. Most women(30; 85.7\%) did not consume caffeine during their pregnancy, while 5 (14.3\%) reported they drank a caffeine drink once a day. All surveyed women $(35 ; 100 \%)$ stated that during pregnancy they did not consume alcohol and did not take any narcotics. Most of the women surveyed (33; 94.3\%) had their first pregnancy check-up by 10 weeks of pregnancy and $2(5.7 \%)$ by week 14. All women (35; 100\%) took $0.4 \mathrm{mg}$ of folic acid, at least three months before, and then during pregnancy up to the $12^{\text {th }}$ week, and then they took multivitamin supplements.

The threat of a premature labor was the reason for hospitalization in 17 (48.6\%) of the pregnant women. In 13 of these cases (37.1\%), this threat was caused by comorbidities, i.e. diabetes, hypertension, anemia, and cholestasis. However, 5 women (14.3\%) were admitted to pregnancy pathology departments because of Twin to Twin Transfusion Syndrome (TTTS).

$20(57.1 \%)$ of the pregnant women responded that their health was good and 15 (42.9\%) of the respondents said that it was satisfactory.

The overall rate of health behaviors of the women was high and was on average $93.9 \pm 10.8$ points (7 sten scores). The values achievedin particular categories of health behaviors are presented in Table 1.

The indicators of health behaviors of the women in multiple pregnancies were high in all categories. However, the highest rate was observed in relation to preventive behaviors.

The indicators of health behaviors (in general and in individual categories), depending on the women's places of residence, education levels, marital status, and the number of successive pregnancies are presented in Tables 2 and 3.

The residents of cities were characterized by a generally higher rate of health behaviors than women living in the rural areas, and the differences between these groups were close to statistical significance $(p=0.08)$. Conversely,

Table 1. General indicators of pregnant health behaviors for each category

\begin{tabular}{|l|c|l|}
\hline Behavior categories & M & SD \\
\hline Proper nutritional habits (PNH) & 3.93 & 0.5 \\
\hline Preventive behaviors (PBs) & 3.99 & 0.5 \\
\hline Positive mental attitude (PMA) & 3.93 & 0.6 \\
\hline Health practices (HPs) & 3.90 & 0.6 \\
\hline
\end{tabular}

$\mathrm{M}$ - medium; \pm SD — standard deviation
Table 2. Index of health behaviors depending on selected variables

\begin{tabular}{|l|c|c|}
\hline Variable & ${ }^{*} \mathbf{M} \pm \mathbf{S D}$ & $\begin{array}{c}\text { Statistical } \\
\text { significance }\end{array}$ \\
\hline $\begin{array}{l}\text { Education } \\
\text { Secondary }\end{array}$ & $92.3 \pm 9.4$ & $\mathrm{Z}=-0.49 ; \mathrm{p}=0.62$ \\
\hline $\begin{array}{l}\text { Higher } \\
\text { Place of residence }\end{array}$ & $94.2 \pm 11.5$ & \\
\hline $\begin{array}{l}\text { City } \\
\text { Rural area }\end{array}$ & $96.4 \pm 10.3$ & $\mathrm{Z}=-1.75 ; p=0.08$ \\
\hline \begin{tabular}{l} 
Marital status \\
\hline Married
\end{tabular} & $90.1 \pm 10.9$ & \\
\hline $\begin{array}{l}\text { Single } \\
\text { Pregnancy }\end{array}$ & $94.5 \pm 10.6$ & $\mathrm{Z}=-0.71 ; p=0.48$ \\
\hline First & $90.2 \pm 12.9$ & \\
\hline Another one & $93.2 \pm 12.4$ & $\mathrm{Z}=-0.07 ; p=0.95$ \\
\hline
\end{tabular}

${ }^{*} \mathrm{M}$ - medium; $\pm \mathrm{SD}$ - standard deviation

within those categories of behavior that were analyzed, the inhabitants of rural areas had a slightly higher index for proper nutritional habits $(\mathrm{PNH})$ and preventive behaviors (PBs) than residents of cities, but these differences were not statistically significant $(p>0.05)$. In the case of the women's highest level of education, there were also no significant differences observed ( $p>0.05$ ). It is worth noting, however, that pregnant women with better education were characterized by a slightly higher general indicator of health behaviors, and higher rates of preventive behavior (PBs) and of health practices (HPs).

Married respondents were characterized by higher general indicators of health behaviors and higher rates for individual health behaviors, but this was not statistically significant ( $p>0.05)$.

Women for whom their current pregnancy was not their first were characterized by higher general indicators of health behaviors and higher indicators for the preventive behavior categories of positive mental attitude and health practices. These indicators were on the verge of statistical significance; but only the health practices rate was statistically significant $(p=0.05)$.

\section{DISCUSSION}

In recent years, an increase in multiple pregnancies around the world has been observed. This is especially true for developed countries, where there is much more access to assisted reproduction techniques. In addition, in the circles of Western culture, the age of women who decide on motherhood has shifted significantly [17]. All this has contributed to increased rates of dizygotic pregnancies, which may be a consequence of complications arising from IVF (in vitro fertilization) and treatments for infertility (ovu- 
Table 3. Index of health behaviors depending on selected variables

\begin{tabular}{|c|c|c|c|c|}
\hline \multirow[t]{2}{*}{ Variable } & $\begin{array}{l}\text { Proper nutritional habits } \\
\text { (PNH) }\end{array}$ & $\begin{array}{l}\text { Preventive behaviors } \\
\text { (PBs) }\end{array}$ & $\begin{array}{l}\text { Positive mental attitude } \\
\text { (PMA) }\end{array}$ & Health practices (HPs) \\
\hline & $* * * M \pm S D$ & $* * * M \pm S D$ & $* * * M \pm S D$ & $* * * M \pm S D$ \\
\hline \multicolumn{5}{|l|}{ Education } \\
\hline Secondary & $3.9 \pm 0.4$ & $3.8 \pm 0.5$ & $3.9 \pm 0.7$ & $3.8 \pm 0.8$ \\
\hline Higher & $3.9 \pm 0.5$ & $4.1 \pm 0.5$ & $3.9 \pm 0.6$ & $3.9 \pm 0.4$ \\
\hline Statistical significance & $\begin{array}{l}Z=-0.85 \\
p=0.40\end{array}$ & $\begin{array}{l}Z=-1.31 \\
p=0.19\end{array}$ & $\begin{array}{l}Z=-0.02 \\
p=0.99\end{array}$ & $\begin{array}{l}Z=-0.04 \\
p=0.97\end{array}$ \\
\hline \multicolumn{5}{|l|}{ Place of residence } \\
\hline City & $3.9 \pm 0.5$ & $3.9 \pm 0.4$ & $3.9 \pm 0.6$ & $3.9 \pm 0.6$ \\
\hline Rural area & $4.0 \pm 0.5$ & $4.0 \pm 0.6$ & $3.9 \pm 0.6$ & $3.9 \pm 0.5$ \\
\hline Statistical significance & $\begin{array}{l}Z=-0.49 \\
p=0.62\end{array}$ & $\begin{array}{l}Z=-0.56 \\
p=0.58\end{array}$ & $\begin{array}{l}Z=-0.10 \\
p=0.92\end{array}$ & $\begin{array}{l}Z=-0.46 \\
p=0.65\end{array}$ \\
\hline \multicolumn{5}{|l|}{ Marital status } \\
\hline Married & $3.9 \pm 0.5$ & $4.0 \pm 0.5$ & $3.9 \pm 0.6$ & $3.9 \pm 0.6$ \\
\hline Single & $3.7 \pm 0.3$ & $3.8 \pm 0.5$ & $3.8 \pm 0.6$ & $3.7 \pm 0.5$ \\
\hline Statistical significance & $\begin{array}{l}Z=-1.07 \\
p=0.28\end{array}$ & $\begin{array}{l}Z=-0.88 \\
p=0.38\end{array}$ & $\begin{array}{l}Z=-0.38 \\
p=0.71\end{array}$ & $\begin{array}{l}Z=-0.97 \\
p=0.33\end{array}$ \\
\hline \multicolumn{5}{|l|}{ Pregnancy } \\
\hline First & $3.98 \pm 0.47$ & $3.86 \pm 0.48$ & $3.86 \pm 0.45$ & $3.76 \pm 0.40$ \\
\hline Another one & $3.89 \pm 0.47$ & $4,10 \pm 0.54$ & $3.99 \pm 0.74$ & $4.02 \pm 0.65$ \\
\hline Statistical significance & $\begin{array}{l}Z=-0.33 \\
p=0.74\end{array}$ & $\begin{array}{l}Z=-1.73 \\
p=0.08\end{array}$ & $\begin{array}{l}Z=-0.57 \\
p=0.57\end{array}$ & $\begin{array}{l}Z=-1.95 \\
p=0.05\end{array}$ \\
\hline
\end{tabular}

$\mathrm{M}$ - medium; \pm SD — standard deviation

lation induction and/or ovarian stimulation without in vitro fertilization) [15]. Multiple monozygotic pregnancies are a matter of chance and their proportion remains unchanged [16]. In our research, the clear majority of women $(32,91.4 \%)$ wrote that their conception occurred naturally. Only 3 (8.6\%) women reported that they used in vitro fertilization.

Every multiple pregnancy is a high-risk pregnancy. There may be various complications, so pregnant women require more frequent medical monitoring [15-17]. In our research, the reason for hospitalization of nearly half of the pregnant women(48.6\%) was a threat of premature birth. In the case of 13 women (37.1\%), this was caused by comorbidities, i.e. diabetes, hypertension, anemia, or cholestasis. However, $14.3 \%$ of these hospitalized omen were diagnosed with Twin to Twin Transfusion Syndrome (TTTS).

Nowadays, researchers from various scientific disciplines study human health behaviors at various stages of life. The intrauterine period is a special stage of life that affects human development and health; and prospective mothers are made aware of health behaviors that contribute to her own and to her child's health and which contribute to the proper course of the pregnancy and fetal development. Research conducted by many authors indicates the relations between a woman's lifestyle during pregnancy and the newborn's state of health. Behaviors that specifically relate to pregnancy include: eating habits, physical activities and the elimination of stimulants [2-15, 19-27].

Regular physical activity during pregnancy is a key element contributing to a woman's well-being. For instance, it influences her mobility, the elimination or reduction of back pain and the prevention excessive weight gain. Above all, regular physical activity is recommended in a physiological pregnancy [19]. A multiple pregnancy, often associated with obstetric complications, may be a real contraindication to physical exertion [20]. In our research, over half of the women we studied (62.9\%) claimed that during their pregnancy (before hospitalization),they were not physically active.

Smoking during pregnancy is a major public health problem. Carbon monoxide and nicotine entering the fetal blood may contribute to intrauterine hypoxia, a low Apgar score at birth and a higher probability of sudden infant death syndrome during infancy. Some authors report that $20-40 \%$ of women smoke cigarettes during pregnancy [10, $11,21,22]$. In our research, more than half of the women we studied $(57.1 \%)$ reported that they had never smoked cigarettes and did not smoke at the time of the survey, whereas $17.1 \%$ of the women reported that they stopped smoking after their pregnancy had been diagnosed. Studies indicate 
the positive trend that the percentage of smoking pregnant women has dropped slightly over the past few years, in line with the fact that the whole population is smoking less [10]. However, it is difficult to estimate the real numbers and the scale of the problem of pregnant women smoking because of insufficient data, including the probability that some pregnant women do not admit to smoking, because of societal pressures [22].

Coffee is commonly consumed during pregnancy. While some of its ingredients, such as caffeine have a strong pharmacological effect, the impact on the unborn child remains unclear. Some reports indicate that the consumption of high quantities of caffeine is associated with the occurrence of miscarriages, premature delivery and fetal growth restriction. Caffeine crosses the placenta, entering fetal blood and its concentration remains the same as in the mother's bloodstream [23]. However, there are still no explicit recommendations to constrain caffeine consumption during pregnancy [24]. The World Health Organization recommends consuming caffeine in quantities not exceeding $300 \mathrm{mg}$, which corresponds to no more than 3 cups of coffee a day [25]. In our research, most of the women we studied (85.7\%) said they did not consume caffeine during pregnancy. Other authors studying women in single pregnancies show that coffee consumption is much more frequent than in our findings [8].

Alcohol and psychoactive substances are stimulants belonging to the so-called neurobehavioral teratogens. Alcohol consumed by the mother enters the fetal blood stream quickly and it reaches concentration levels similar to those in the mother's bloodstream. So far, no safe level of alcohol consumption during pregnancy has been established, and studies show that even the smallest amount can be harmful [11]. Despite the destructive effects of alcohol on fetal development, its consumption during pregnancy still occurs. Some reports indicate that about $18 \%$ of women continue to drink alcoholic beverages during pregnancy [26]. In our research, all the pregnant women we studied reported that they did not consume alcohol during their pregnancy. Recent reports show that the use of psychoactive drugs in Poland is rare [10]. In our research, the women we studied reported that they did not take any narcotic substances.

Many authors declare that the use of stimulants during pregnancy is relatively more frequent among women who are less educated, divorced, single and who remain in informal relationships $[10,11]$. In our research, most of the pregnant women we studied $(85.7 \%)$ were married, and over half of the respondents (71.4\%) had higher education. In addition, in the studied group of women, the in frequent use of stimulants may have been a result of their increased attention to pro-health behaviors arising from their high-risk pregnancies, i.e. multiple pregnancies.
During pregnancy, the mother's need for particular nutrients increases. The most important of these is folic acid [29]. Taking it reduces the risk of birth defects, obstetrical pathologies and the development of chronic diseases in adulthood [30]. All women in our study $(35 ; 100 \%)$ took $0.4 \mathrm{mg}$ of folic acid, at least three months before and then during their pregnancies, up to 12 weeks; following this, they took multivitamin supplements.

Our research results showed that the overall rate of the health behaviors of the examined pregnant women $(93.9 \pm 10.8)$ was high (7 sten scores). Moreover, we observed high health behavior rates for particular categories in the examined pregnant women (all above $3.90 \pm 0.6$ ). As previously mentioned, a multiple pregnancy is a condition of increased obstetric risk. In Juczyński's study of 61 women in high-risk pregnancies using the Health Behavior Inventory, he observed that the average general index of health behaviors $(90.18 \pm 12.78$, i.e. 6 sten scores) was higher than that in healthy women [28]. The same author observed high rates of preventive behaviors (3.91 \pm 0.78$)$, positive mental attitudes $(3.94 \pm 0.6)$ and health practices $(3.80 \pm 0.69)$, compared with those of non-pregnant women. The lowest rate observed during his research related to the observance of proper nutritional habits $(3.38 \pm 0.71)$. Slightly different results were obtained by Boguszewski et al. [3] in their research among healthy women during pregnancy. Their study included 214 pregnant women and 268 healthy women (as a control group); and they found an average rate of health behaviors $(87.56 \pm 12.59)$. In the study by Boguszewski et al. [3], positive mental attitude $(3.69 \pm 0.68)$ and health practices $(3.68 \pm 0.67)$ rated the highest, followed by proper nutritional habits (3.66 \pm 0.68$)$ and preventive behaviors (3.56 0.71). It is worth noticing that these results were higher than those of their control group.

Our research findings showed that pregnant women pay attention to their lifestyle. They understand that pregnancy is a period of special concern for their own health.

The implementation of pro-health behaviors in the preconception and prenatal period is a guarantee of improvement of a pregnant woman's well-being as well as the obstetric condition. It seems important therefore, to ensure that effective methods of health education are constantly implemented, involving as many health care workers as possible who are in contact with women during the entire course of their pregnancies $[7,12,17]$.

\section{CONCLUSIONS}

The overall rates of health behaviors of women in a multiple pregnancy, and indicators for individual categories of behavior were high. However, the highest rate observed was with preventive behaviors. The value indicators of the health behaviors of the pregnant women were not dependent on the variables adopted in this study. 


\section{REFERENCES}

1. SkrzypekM. Psychosocjosomatyka-ewolucja, przedmiot badań, funkcje. W: Barański J, Piątkowski W. (red.) Zdrowie i choroba. Wybrane problemy socjologii medycyny. Oficyna Wydawnicza ATUT, Wrocław 2002: 57.

2. Alkaabi MS, Alsenaidi LK, Mirghani H.Women's knowledge and attitude towards pregnancy in a high-income developing country. J Perinat Med. 2015; 43(4):445-448, doi: 10.1515/jpm-2013-0296, indexed in Pubmed: 24468597.

3. Boguszewski D, Adamczyk JG, Tomaszewski W, et al. Evaluation of the Health-related Behaviour of Pregnant Women from Warsaw, Poland. Iran J Public Health. 2018; 47(1): 57-63, indexed in Pubmed: 29318118.

4. Gacek M. Some health behaviours and selected health status coefficients in group of pregnant women. Prob HigEpidemiol. 2010; 91(1): 48-53.

5. Wilkinson SA, McIntyre HD. Evaluation of the'healthy start to pregnancy' early antenatal health promotion workshop: a randomized controlled trial. BMC Pregnancy Childbirth. 2012; 12: 131, doi: 10.1186/1471-239312-131, indexed in Pubmed: 23157894.

6. O'Keeffe LM, Dahly DL, Murphy M, et al. Positive lifestyle changes around the time of pregnancy: a cross-sectional study. BMJ Open. 2016; 6(5): e010233, doi: 10.1136/bmjopen-2015-010233, indexed in Pubmed: 27154477.

7. OlejniczakD, Krakowiak K. Asswssing the Reed for health education of pregnant women in the life style and restfeeding. Nowa Ped. 2013; 3: 97-105.

8. Pieszko M, Ciesielska-Piotrowicz J, Skotnicka M, et al. Behaviour health pregnant women with secondary and higher education - preliminary studies. Pediatria i Medycyna Rodzinna. 2017; 13(1): 94-102, doi: 10.15557/pimr.2017.0009.

9. Phelan S. Pregnancy: a "teachable moment" for weight control and obesity prevention. Am J Obstet Gynecol. 2010; 202(2): 135.e1-135.e8, doi: 10.1016/j.ajog.2009.06.008.

10. Raport z badania: Zachowania zdrowotne kobiet w ciąży. Państwowa Inspekcja Sanitarna, 28-58 Warszawa, 2017.

11. Raport: Zachowania zdrowotne kobiet w ciąży. Instytut Medycyny Wsi im. Witolda Chodźki, 88-101 Lublin, 2013.

12. Grzesik-Gąsior J, Granisz E, Bień A, et al. Midwife in the prevention of preterm birth. J Educ Health Sport. 2017; 7(8): 1461-1476.

13. Jackson RA, Stotland NE, Caughey AB, et al. Improving diet and exercise in pregnancy with Video Doctor counseling: a randomized trial. Patient Educ Couns. 2011; 83(2): 203-209, doi: 10.1016/j.pec.2010.05.019, indexed in Pubmed: 21459255

14. Krzepota J, Putek-Szeląg E. Nutritional habits in the light of general health behaviours of pregnant women. Ann Agric Environ Med. 2014; 21(2):425428, doi: 10.5604/1232-1966.1108618, indexed in Pubmed: 24959803.

15. Małecka-Włoch A. [Women's health awareness in the preconceptive period and during pregnancy]. Przegl Lek. 2015; 72(2): 49-52, indexed in Pubmed: 26727742.
16. Allen $\mathrm{BD}$, Adashi $\mathrm{EY}$, Jones $\mathrm{HW}$. On the cost and prevention of iatrogenic multiple pregnancies. Reprod Biomed Online. 2014; 29(3): 281-285, doi: 10.1016/j.rbmo.2014.04.012, indexed in Pubmed: 24934626.

17. Filipecka-Tyczka D. Medical care for a pregnant woman with a multiple pregnancy. Post Nauk Med. 2016; 29(7): 475-482.

18. Smith LK, Manktelow BN, Draper ES, et al. Trends in the incidence and mortality of multiple births by socioeconomic deprivation and maternal age in England: population-based cohort study. BMJ Open. 2014; 4(4): e004514, doi: 10.1136/bmjopen-2013-004514, indexed in Pubmed: 24699461.

19. Gdańska A, Ślężyńska M, Wiśniewska D. Factors affecting the physical activity and its effect during pregnancy. J Educ Health Sport. 2016; 6(9): 699-711.

20. Urtnowska K, Bułatowicz I, Ludwikowski G, et al. Secure forms of physical activity for pregnant women. J Educ Health Sport. 2016; 6(5): 291-297.

21. Popken-Haładus B, Żurawicka D, Zimnowoda M. Palenietytoniu w ciąży-badaniawłasne. W: Wojtal M, . (red.). Wybraneaspektyopiekipielęgniarskiej i położniczej w różnychspecjalnościachmedycyny. Opole: Instytut Śląski. 2013: 29-40.

22. Pawłowska-Muc AK, Łepecka-Klusek C, Pilewska-Kozak AB, et al. Cigarette smoking in pregnancy. J Educ Health Sport. 2016; 6(1): 73-84.

23. Domingues eP, Shang FLT, Chiarini-Garcia H, et al. Caffeine Intake during Pregnancy: What Are the Real Evidences? J Pharm Pharmacol. 2017; 5: 249-260.

24. van der Hoeven T, Browne JL, Uiterwaal CS, et al. Antenatal coffee and tea consumption and the effect on birth outcome and hypertensive pregnancy disorders. PLoS One. 2017; 12(5): e0177619, doi: 10.1371/journal.pone.0177619, indexed in Pubmed: 28520809.

25. Chen LW, Wu Yi, Neelakantan N, et al. Maternal caffeine intake during pregnancy and risk of pregnancy loss: a categorical and dose-response meta-analysis of prospective studies. Public Health Nutr. 2016; 19(7): 1233-1244, doi: 10.1017/S1368980015002463, indexed in Pubmed: 26329421.

26. Baranowska AS. Fetal alcohol syndrom (FAS) as threat to a child's development. J Educ Health Sport. 2016; 6(3): 148-158.

27. Andersen $A M N$, Andersen PK, Olsen J, et al. Moderate alcohol intake during pregnancy and risk of fetal death. Int J Epidemiol. 2012; 41(2): 405-413, doi: 10.1093/ije/dyr189, indexed in Pubmed: 22253313.

28. Juczyński Z. Narzędziapomiaru w promocji i psychologiizdrowia. Wydanie II. PracowniaTestówPsychologicznych, Warszawa. ; 2009: 110-116.

29. Grzelak T, Suliga K, Sperling M, et al. Evaluation of dietary supplements use among pregnant women or planning pregnancy. Forum Zaburzeń Metabolicznych. 2016; 7(1): 8-15.

30. Makowska-Donajska M, Hirnle L. Suplementation of vitamins and mineralsduring pregnancy. Gin Perinat Prakt. 2017; 2(4): 166-172. 